\title{
A $\beta$-Induced Synaptic Alterations Require the E3 Ubiquitin Ligase Nedd4-1
}

\author{
Elizabeth M. Rodrigues, Samantha L. Scudder, Marisa S. Goo, and Gentry N. Patrick \\ University of California San Diego, Section of Neurobiology, Division of Biological Sciences, La Jolla, California 92093-0347
}

\begin{abstract}
Alzheimer's disease (AD) is a neurodegenerative disease in which patients experience progressive cognitive decline. A wealth of evidence suggests that this cognitive impairment results from synaptic dysfunction in affected brain regions caused by cleavage of amyloid precursor protein into the pathogenic peptide amyloid- $\beta(\mathrm{A} \beta)$. Specifically, it has been shown that A $\beta$ decreases surface AMPARs, dendritic spine density, and synaptic strength, and also alters synaptic plasticity. The precise molecular mechanisms by which this occurs remain unclear. Here we demonstrate a role for ubiquitination in $\mathrm{A} \beta$-induced synaptic dysfunction in cultured rat neurons. We find that $\mathrm{A} \beta$ promotes the ubiquitination of AMPARs, as well as the redistribution and recruitment of Nedd4-1, a HECT E3 ubiquitin ligase we previously demonstrated to target AMPARs for ubiquitination and degradation. Strikingly, we show that Nedd4- 1 is required for A $\beta$ induced reductions in surface AMPARs, synaptic strength, and dendritic spine density. Our findings, therefore, indicate an important role for Nedd4-1 and ubiquitin in the synaptic alterations induced by $\mathrm{A} \beta$.
\end{abstract}

Key words: abeta; AMPA receptor; endocytosis; Nedd4-1; ubiquitin

\section{Significance Statement}

Synaptic changes in Alzheimer's disease (AD) include surface AMPAR loss, which can weaken synapses. In a cell culture model of $\mathrm{AD}$, we found that AMPAR loss correlates with increased AMPAR ubiquitination. In addition, the ubiquitin ligase Nedd4-1, known to ubiquitinate AMPARs, is recruited to synapses in response to A $\beta$. Strikingly, reducing Nedd4-1 levels in this model prevented surface AMPAR loss and synaptic weakening. These findings suggest that, in AD, Nedd4-1 may ubiquitinate AMPARs to promote their internalization and weaken synaptic strength, similar to what occurs in Nedd4-1's established role in homeostatic synaptic scaling. This is the first demonstration of $\mathrm{A} \beta$-mediated control of a ubiquitin ligase to regulate surface AMPAR expression.

\section{Introduction}

Alzheimer's disease $(\mathrm{AD})$ is a prevalent neurodegenerative disease characterized by extracellular amyloid plaques, intracellular neurofibrillary tangles, synaptic loss, and cognitive decline. Amyloid plaques are primarily composed of amyloid- $\beta$ peptides $(\mathrm{A} \beta)$, and evidence suggests that the proteolytic processing of amyloid precur-

Received Aug. 5, 2015; revised Nov. 23, 2015; accepted Dec. 15, 2015.

Author contributions: E.M.R., S.L.S., M.S.G., and G.N.P. designed research; E.M.R., S.L.S., and M.S.G. performed research; E.M.R., S.L.S., M.S.G., and G.N.P. analyzed data; E.M.R., S.L.S., M.S.G., and G.N.P. wrote the paper.

This work was supported by National Institutes of Health Neural Circuits Postdoctoral Training Grant T32 NS007220 to E.M.R., National Science Foundation Graduate Research Fellowships to S.L.S. and M.S.G., National Institutes of Health Grant NS060847 to G.N.P., National Institutes of Health Training Grant T32 AG00216 to S.L.S., and Center for Systems Biology Grant P50-GM085764. We thank Edward Koo and Floyd Sarsoza (University of California-San Diego) for 7PA2 cells and assistance with ELISA measurements; Stuart Lipton and Mohd Waseem Akhtar (Sanford Burnham) for helpful discussions and reagents; Adrian Lozada and Darwin Berg (University of California-San Diego) for TdTomato lentivirus; members of the G.N.P. laboratory for helpful discussion; and Lara Dozier for technical assistance.

The authors declare no competing financial interests.

Correspondence should be addressed to Dr. Gentry N. Patrick, Section of Neurobiology, Division of Biological Sciences, 9500 Gilman Drive, La Jolla, CA 92093-0347. E-mail: gpatrick@ucsd.edu.

DOI:10.1523/JNEUROSCI.2964-15.2016

Copyright $\odot 2016$ the authors $\quad 0270-6474 / 16 / 361590-06 \$ 15.00 / 0$ sor protein (APP) to generate $\mathrm{A} \beta$ plays a causal role in disease pathogenesis (Hardy and Selkoe, 2002). Increased levels of soluble oligomeric $\mathrm{A} \beta$ correlate with the severity of cognitive impairment in AD (Lue et al., 1999; McLean et al., 1999). Furthermore, a large body of research suggests that $A \beta$ causes synaptic defects to account for this cognitive decline (Selkoe, 2002), but the mechanisms underlying $\mathrm{A} \beta$-induced synaptic alterations remain uncertain.

At glutamatergic excitatory synapses, synaptic strength and plasticity are, in large part, determined by the trafficking of glutamate receptors to and from the surface of the postsynaptic membrane (Shepherd and Huganir, 2007). Several studies reveal that elevated levels of $\mathrm{A} \beta$ lead to the loss of glutamate receptors (Snyder et al., 2005; Hsieh et al., 2006). Indeed, A $\beta$ causes AMPAR endocytosis and depressed AMPAR-mediated synaptic transmission (Almeida et al., 2005; Hsieh et al., 2006; Alfonso et al., 2014). This is presumed to underlie impairments in synaptic plasticity and cognition associated with AD (Cleary et al., 2005; Chang et al., 2006; Shankar et al., 2008). Therefore, identifying the molecular mechanisms underlying $\mathrm{A} \beta$-induced removal of AMPARs from synapses is of great interest. 
Several lines of research demonstrate that synaptic activation of AMPARs causes their ubiquitination, internalization, and subsequent endocytic sorting to the lysosome for degradation (Ehlers, 2000; Schwarz et al., 2010; Lussier et al., 2011). Our group previously identified Nedd4-1 as a ubiquitin ligase involved in this process and demonstrated activity-dependent synaptic recruitment of this ligase (Schwarz et al., 2010; Scudder et al., 2014). Here we ask whether ubiquitination is involved in $\mathrm{A} \beta$-induced downregulation of surface AMPARs. We show that $\mathrm{A} \beta$ promotes the ubiquitination of AMPARs, as well as the redistribution of Nedd4-1 into dendritic spines. Finally, we show that RNAi-mediated knockdown of Nedd4-1 blocks A $\beta$-induced reductions in surface AMPARs, synaptic strength, and spine density. This study provides the first evidence for Nedd4-1 and the ubiquitination of AMPARs in synaptic alterations induced by $\mathrm{A} \beta$.

\section{Materials and Methods}

Antibodies and reagents. Antibodies were as follows: pAb GFP (Invitrogen); pAb (C-term) GluA1, pAb GluA2/3, and pAb Nedd4-1 (Millipore); mAb tubulin (Sigma); mAb ubiquitin (P4D1; Santa Cruz Biotechnology); and $\mathrm{mAb}$ hemagglutinin (HA; Covance). Reagents were as follows: AMPA, TTX, and bicuculline (Tocris Bioscience); $N$-ethylmaleimide (Sigma); leupeptin (Millipore); and EGTA (Calbiochem).

Neuronal cultures. Rat dissociated hippocampal or cortical neurons from postnatal day 1 pups of either sex were plated at a density of 45,000 cells $/ \mathrm{cm}^{2}$ onto poly-D-lysine-coated coverslips (hippocampal cultures) or poly D-lysine-coated 6 -well plastic dishes at $\sim 500,000$ cells per well (cortical cultures) and were maintained in B27 supplemented Neurobasal media (Invitrogen) until $\geq 14 \mathrm{~d}$ in vitro (DIV), as previously described (Schwarz et al., 2010; Scudder et al., 2014).

Naturally secreted and synthetic $A \beta$. Chinese hamster ovary $(\mathrm{CHO})$ cells stably expressing human APP751 with the Val717Phe mutation (7PA2 cells, a generous gift from E. Koo) (Podlisny et al., 1995) were cultured in DMEM with 10\% FBS and penicillin/streptomycin. Neurobasal media with B27 supplement (Invitrogen) was conditioned with confluent 7PA2 cells, cleared of cells by centrifugation, and concentrated using YM-3 Centriprep filters (Millipore). $\mathrm{A} \beta_{1-42}$ concentration was assessed by ELISA, using monoclonal antibody MM26-2.1.3 (Mayo Clinic) as capture and HRP-conjugated 6E10 (Covance) antibody as reporter (generously provided by E. Koo). Control conditioned media $(\mathrm{CM})$ was prepared in a similar fashion from $\mathrm{CHO}$ cells. For synthetic $\mathrm{A} \beta$ experiments, human synthetic $\mathrm{A} \beta_{1-42}$ (GenicBio) was dissolved in DMSO and then oligomerized in MEM using published protocols (Talantova et al., 2013) (generously provided and prepared by S. Lipton and M. Akhtar). Oligomeric stock concentration was determined through dynamic light scattering to be $25 \mu \mathrm{M}$, and final treatment concentration was $250 \mathrm{~nm}$. DMSO alone was used as a control.

Infections. Lentivirus expressing Nedd4-1 shRNA hairpin was described previously (Schwarz et al., 2010; Scudder et al., 2014). Dissociated hippocampal or cortical cultures were infected with control lentivirus or lentivirus expressing Nedd4-1 shRNA at DIV 10-12, and experiments were conducted 3-5 d later. For redistribution experiments, dissociated hippocampal cultures were infected with Sindbis virion expressing HAtagged Nedd4-1 at DIV 18-22 and allowed to express for 20-24 h. To fill cells for spine density analysis, neurons were infected with Sindbis virion expressing tdTomato for $13 \mathrm{~h}$ or lentivirus expressing GFP for $4 \mathrm{~d}$. Viral titer and transduction efficiency were monitored to ensure equal expression of constructs.

Electrophysiology. For whole-cell voltage-clamp recordings of mEPSCs, dissociated hippocampal neurons were bathed at room temperature in a HEPES-buffered saline solution (in $\mathrm{mM}$ as follows: 119 $\mathrm{NaCl}, 5 \mathrm{KCl}, 2 \mathrm{CaCl}_{2}, 2 \mathrm{MgCl}_{2}, 30$ glucose, 10 HEPES, pH 7.2, with $1 \mu \mathrm{M}$ TTX and $10 \mu \mathrm{M}$ bicuculline). The electrode internal solution contained the following (in mM): $10 \mathrm{CsCl}, 105 \mathrm{CsMeSO}_{3}, 0.5 \mathrm{ATP}, 0.3 \mathrm{GTP}, 10$ HEPES, 5 glucose, $2 \mathrm{MgCl}_{2}$, and 1 EGTA, $\mathrm{pH}$ 7.2. Electrode resistances ranged from 2.5 to $4.5 \mathrm{M} \Omega$. Holding potential for all cells was $-70 \mathrm{mV}$.
mEPSCs were analyzed using ClampFit 10.3 (Molecular Devices). Infected cells were identified through GFP fluorescence, and pyramidallike neurons were chosen. Experimenters were blinded to condition during data collection and analysis.

Biotinylation of surface AMPARs. To detect surface AMPARs, cultured cortical neurons were rinsed with PBS-MC (10 mM phosphate buffer, $2.7 \mathrm{~mm} \mathrm{KCl}, 137 \mathrm{~mm}, \mathrm{NaCl}, 1 \mathrm{~mm} \mathrm{CaCl}_{2}, 0.5 \mathrm{~mm} \mathrm{MgCl}_{2}, \mathrm{pH}$ 7.4), placed on ice, rinsed with cold PBS-MC, incubated with $1 \mathrm{mg} / \mathrm{ml}$ Sulfo-NHS-LC-Biotin (Pierce) for $15 \mathrm{~min}$ at $4^{\circ} \mathrm{C}$, and then rinsed again with $0.1 \%$ BSA in PBS-MC. Cells were scraped into RIPA buffer (50 mм Tris- $\mathrm{HCl}, 150 \mathrm{~mm} \mathrm{NaCl}, 1 \% \mathrm{NP}-40,0.5 \% \mathrm{Na}$-deoxycholate, and $0.1 \%$ SDS) with protease inhibitors. An equal amount of protein per sample was incubated with neutravidin-agarose (Pierce) overnight at $4^{\circ} \mathrm{C}$. Agarose was then rinsed 3 times, and bound proteins were eluted into SDS sample buffer by boiling. Quantitative Western blots were performed on biotinylated proteins using antibodies against GluA1 (1:1000) or Nedd4-1 (1:5000).

Immunoprecipitations. Leupeptin $(100 \mu \mathrm{g} / \mathrm{ml})$ was administered $1 \mathrm{~h}$ before an overnight treatment with $\mathrm{CHO}$ or 7PA2 CM. Cultured cortical neurons were lysed in precipitation buffer (in mM as follows: $100 \mathrm{NaCl}$, $10 \mathrm{Na}_{2} \mathrm{HPO}_{4}, 5$ EDTA, 5 EGTA with $1 \%$ Triton X-100, 0.1\% SDS, $25 \mu \mathrm{M}$ MG-132, 25 mu N-ethylmaleimide, and protease inhibitors). Homogenates were cleared by centrifugation. For immunoprecipitations, cleared lysates were incubated at $4^{\circ} \mathrm{C}$ overnight with anti-GluA2/3 pAb antibodies because this antibody efficiently immunoprecipitated both GluA1 and GluA2 in our lysis buffer conditions that do not disrupt the tetramer receptor complex. Protein A agarose beads (Pierce) were added for an additional $2 \mathrm{~h}$. Immunoprecipitates were then washed, boiled in sample buffer, and run in Western blot analysis.

Western blot analysis. Total protein lysates were generated by scraping cells into RIPA buffer with protease inhibitors, incubating for $20 \mathrm{~min}$ at $4^{\circ} \mathrm{C}$, and then clearing by centrifugation at $14,000 \mathrm{rpm}$ at $4^{\circ} \mathrm{C}$. Protein concentration was determined by BCA protein assay (Pierce), and equal protein amounts were loaded. Samples were boiled with sample buffer, resolved on $8 \%$ SDS-PAGE, and probed with primary and then secondary HRP-conjugated antibodies. Blots were digitized by scanning films, and band intensities were quantified using National Institutes of Health ImageJ. For quantification of total GluA1 levels, band intensities in each condition were normalized to tubulin band mean intensity from the same sample. Statistical significance was determined through unpaired $t$ tests.

Immunostaining. After infections and drug treatments, neurons were washed with cold PBS-MC and fixed with a $4 \%$ PFA/sucrose solution for 10 min. Cells were permeabilized with $0.2 \%$ Triton X-100 and 2\% BSA in PBS-MC for $20 \mathrm{~min}$, followed by a $1 \mathrm{~h}$ block in 5\% BSA in PBS-MC. Primary and secondary antibodies were diluted into $2 \%$ BSA in PBS-MC and applied to neurons, overnight at $4^{\circ} \mathrm{C}$ for primary and $1 \mathrm{~h}$ at room temperature for secondary. Coverslips were mounted onto glass slides for confocal imaging.

Confocal microscopy and image analysis. All images were acquired with a Leica DMI6000 inverted microscope equipped with a Yokogawa Nipkon spinning disk confocal head, an Orca ER high-resolution black and white cooled CCD camera $(6.45 \mu \mathrm{m} /$ pixel at $1 \times)$, Plan Apochromat $63 \times / 1.4$ numerical aperture objective, and an argon/krypton $100 \mathrm{~mW}$ air-cooled laser for 488/568/647 nm excitations. Maximum projected $Z$-stacks were analyzed with National Institutes of Health ImageJ. For redistribution experiments, dendrites were straightened using ImageJ, and a custom macro was used to run the Find Maxima function through a range of noise tolerance levels, as previously described (Scudder et al., 2014). Fluorescence within spines was determined through manual spine tracing and a custom ImageJ macro. Integrated density within spines was compared with total integrated density to determine the fraction of total HA signal present in spines, and values were normalized to control ( $\mathrm{CHO}$ ). For spine density analysis, dendrites were straightened using ImageJ, and spine density was the number of manually counted spines divided by dendrite segment length. Experimenters were blinded to condition during data collection and analysis, and statistical significance was determined through unpaired $t$ tests using Prism software (GraphPad). 
A

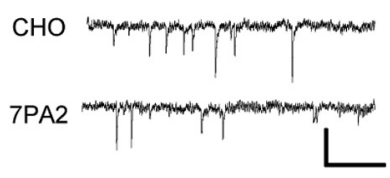

E

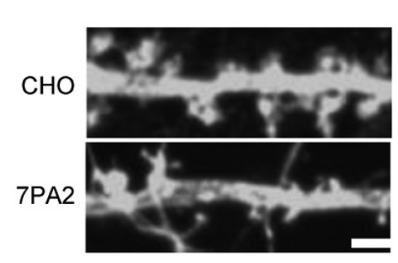

G

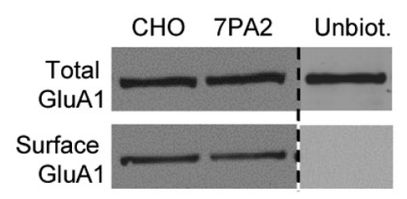

B

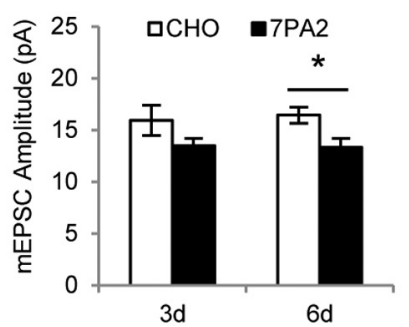

F

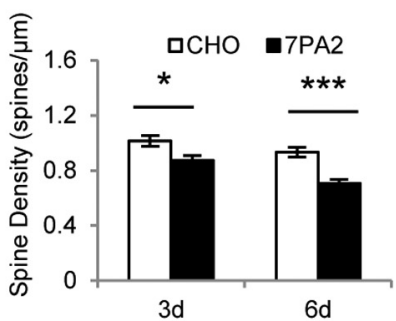

H

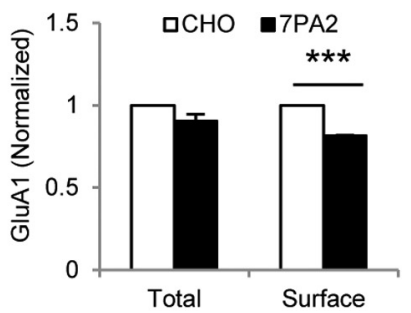

C

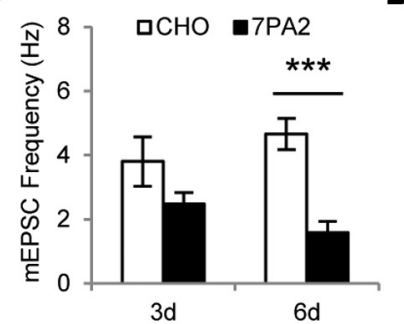

I

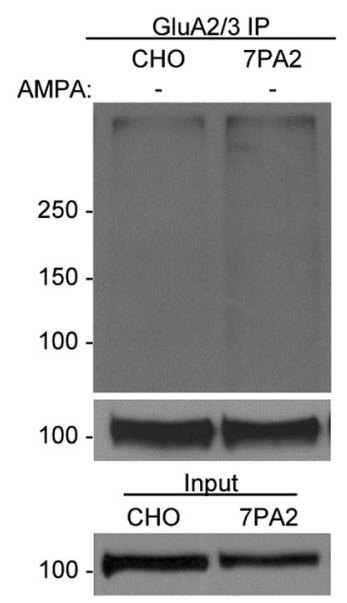

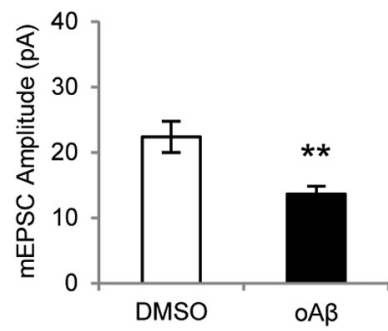

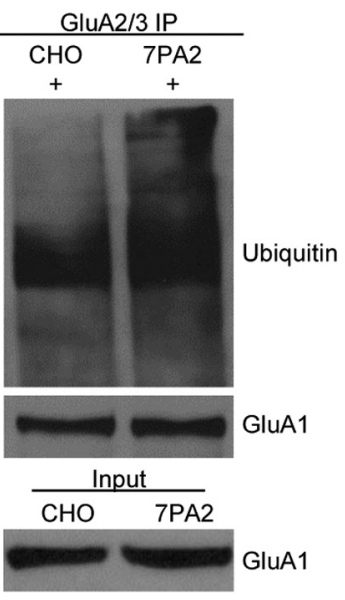

Figure 1. A $\beta$-induced synaptic alterations coincide with enhanced AMPAR ubiquitination. $A$, Representative traces of mEPSCs from each condition indicated. Calibration: $500 \mathrm{~ms}, 20 \mathrm{pA}$. $\boldsymbol{B}, \boldsymbol{C}$, Mean mEPSC amplitude (B) and frequency (C) for neurons (DIV 16-20) treated with CHO or 7PA2 CM for 3 or $6 \mathrm{~d}$. D, Mean mEPSC amplitude for neurons treated with DMSO or oligomeric A $\beta$ for $3 \mathrm{~d}$. $\boldsymbol{E}$, Representative immunofluorescent images of dendrites treated with $\mathrm{CH} 0$ or 7 PA2 $\mathrm{CM}$ for $6 \mathrm{~d}$. Scale bar, $5 \mu \mathrm{m}$. $\boldsymbol{F}$, Quantification of spine density from conditions displayed in $\boldsymbol{E}$. $\boldsymbol{G}$, Representative Western blot of total and biotinylated surface GluA1 in neurons treated with $\mathrm{CH} 0$ or 7PA2 CM for $3 \mathrm{~d}$. $\boldsymbol{H}$, Quantification of immunoblots for total and surface GluA1, normalized to $\mathrm{CH} 0$. $\boldsymbol{I}$, Representative immunoblot depicting enhanced AMPA-induced (100 $\mu \mathrm{m}, 10 \mathrm{~min}$ ) ubiquitination of AMPARs following a $14 \mathrm{~h}$ treatment with $7 \mathrm{PA2} C \mathrm{CM} .{ }^{*} p<0.05$. ${ }^{* *} p<0.01$. ${ }^{* * *} p<0.001$.

\section{Results}

$A \beta$-induced synaptic alterations coincide with enhanced AMPAR ubiquitination

As previously reported, $\mathrm{A} \beta$ alters both synaptic strength and dendritic spine morphology (Hsieh et al., 2006; Shankar et al., 2008). We recorded mEPSCs from mature cultured hippocampal neurons and found that $5 \mathrm{~nm}$ naturally secreted $\mathrm{A} \beta$ from $7 \mathrm{PA} 2 \mathrm{CM}$ began to reduce mEPSC amplitude and frequency compared with control $\mathrm{CHO} \mathrm{CM}$ after $3 \mathrm{~d}$ of treatment, and this difference reached statistical significance after $6 \mathrm{~d}$ ( $\mathrm{CHO}$, amplitude: $16.44 \pm 0.77$ pA, frequency: $4.66 \pm 0.48 \mathrm{~Hz}, n=15$ cells; 7PA2, amplitude: $13.32 \pm 0.85 \mathrm{pA}$; frequency: $1.59 \pm 0.34 \mathrm{~Hz}, n=10$ cells; $p=0.014$ and $p<0.001$, respectively; Fig. $1 A-C$ ). To test the specificity of this effect to $A \beta$, we used purified synthetic human $A \beta$ in another set of experiments. $A \beta$ was sufficient to induce synaptic depression because $250 \mathrm{~nm}$ oligomeric $\mathrm{A} \beta_{1-42}$ also reduced mEPSC amplitude compared with vehicle alone. This difference was significant after only $3 \mathrm{~d}$ of treatment, although no significant frequency changes were observed (DMSO, amplitude: $22.37 \pm 2.41 \mathrm{pA}$, frequency: $2.15 \pm 0.73 \mathrm{~Hz}, n=7$ cells; oligomeric $\mathrm{A} \beta$, amplitude: $13.66 \pm 0.79 \mathrm{pA}$, frequency: $1.57 \pm 0.34 \mathrm{~Hz}, n=9$ cells; $p=0.002$ and $p=0.723$, respectively; Fig. $1 D$ ). Using GFP as a cytoplasmic marker, we additionally found that spine density significantly decreased after 3 and $6 \mathrm{~d}$ of treatment with 7PA2 $\mathrm{CM}(\mathrm{CHO} 3 \mathrm{~d}: 1.01 \pm 0.04$ spines $/ \mu \mathrm{m}$, $n=39$ dendrites; 7PA2 3 d: $0.87 \pm 0.04$ spines $/ \mu \mathrm{m}, n=36$ dendrites; $p=0.011$; CHO 6 d: $0.93 \pm 0.04$ spines $/ \mu \mathrm{m}, n=68$ dendrites; 7PA2 6 d: $0.7 \pm 0.03$ spines $/ \mu \mathrm{m}, n=70$ dendrites; $p<0.001$; Fig. $1 E, F)$.

In parallel, we evaluated the effect of $A \beta$ on surface AMPAR levels. We performed surface biotinylation experiments on neurons treated with 7PA2 or $\mathrm{CHO} \mathrm{CM}$ and found the GluA1 subunit of AMPARs significantly reduced from the surface of neurons after $3 \mathrm{~d}$ of treatment with 7PA2 CM, whereas total GluA1 amounts remained relatively unchanged (normalized surface level: $0.81 \pm 0.005, n=5, p<0.001$; normalized total level: $0.9 \pm 0.04, n=5, p>0.05$; Fig. $1 G, H)$. Therefore, in our culture model system, we recapitulated several $\mathrm{A} \beta$-induced synaptic alterations, including the increased AMPAR internalization previously reported by others (Almeida et al., 2005; Hsieh et al., 2006). However, the mechanisms by which A $\beta$ causes AMPAR internalization remain unclear. We and others have reported that activation of AMPARs leads to their ubiquitination and subsequent internalization (Ehlers, 2000; Schwarz et al., 2010; Lussier et al., 2011). We hypothesized that $A \beta$-induced AMPAR internalization could involve receptor ubiquitination. To evaluate receptor ubiquitination, which would precede receptor loss, we treated neurons with $A \beta$ for a shorter overnight duration, stimulated AMPARs with the agonist AMPA, immunoprecipitated AMPARs, and then probed for ubiquitin. We demonstrated that agonist-mediated ubiquitination of AMPARs substantially increased in the presence of 7PA2 CM (Fig. 1I), suggesting that $\mathrm{A} \beta$-induced AMPAR internalization may occur via a ubiquitinmediated process. 
A

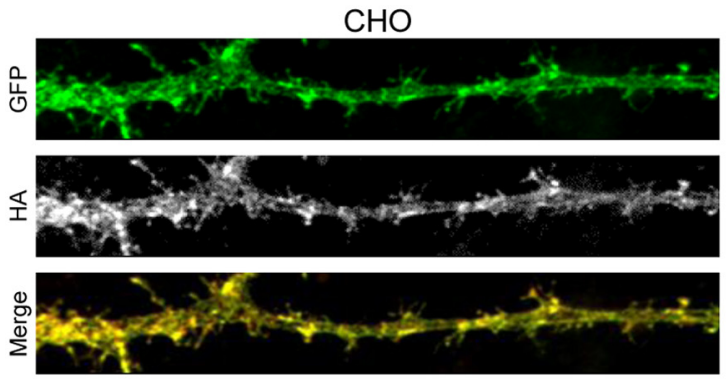

B

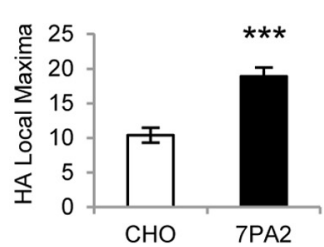

C

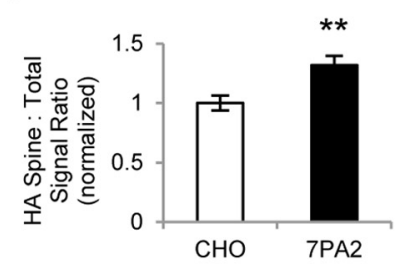

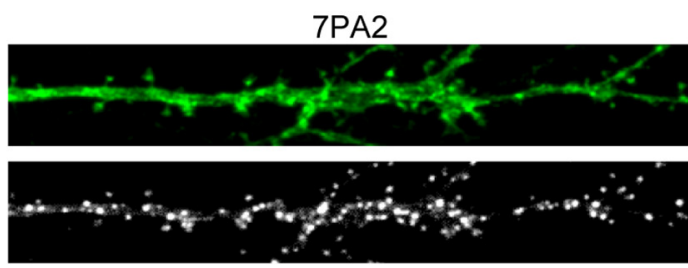

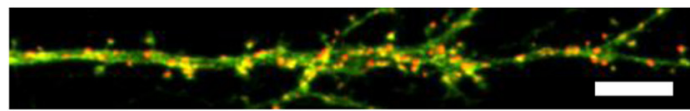

D

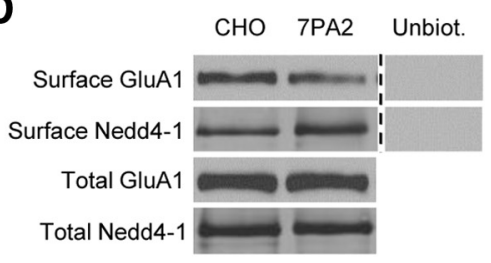

E

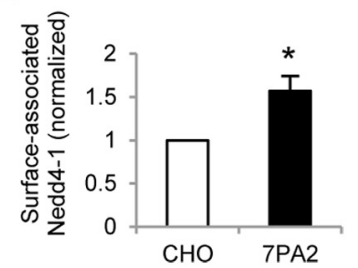

Figure 2. A $\beta$ promotes Nedd4-1 redistribution into dendritic spines and increases Nedd4-1 association with surface proteins. $\boldsymbol{A}$, Representative immunofluorescent images of hippocampal dendrites expressing HA-tagged Nedd4-1, treated with CH0 or 7PA2 CM for 23 h and stained with anti-GFP (green) and anti-HA (white) antibodies. Scale bar, $5 \mu$ m. $B$, Quantification of HA-Nedd4-1 fluorescence local maxima from conditions displayed in $\boldsymbol{A}$. $\boldsymbol{C}$, Normalized ratio of spine to total HA levels between conditions in $\boldsymbol{A}$. $\boldsymbol{D}$, Representative Western blot of surface and total Nedd4-1 and GluA1 in neurons treated with CH0 or 7PA2 CM for $3 \mathrm{~d}$. E, Quantification of immunoblots for surface-associated Nedd4-1, normalized to $\mathrm{CH0}$. ${ }^{*} p<0.05$. ${ }^{* *} p<0.01 .{ }^{* *} p<0.001$.

\section{A $\boldsymbol{\beta}$ promotes Nedd4-1 redistribution into dendritic spines and increases Nedd4-1 association with surface proteins} Our group previously demonstrated that Nedd4- 1 is a ubiquitin ligase that targets AMPARs for ubiquitination, internalization, and subsequent sorting to the lysosome for degradation (Schwarz et al., 2010). Activation of AMPARs causes Nedd4-1 to redistribute into dendritic spines, and activity-induced AMPAR ubiquitination does not occur when Nedd4-1 is knocked down (Schwarz et al., 2010; Scudder et al., 2014). Because A $\beta$ promoted AMPAR ubiquitination and internalization, we hypothesized that $\mathrm{A} \beta$ might regulate Nedd4- 1 trafficking into dendritic spines. To evaluate this, we infected hippocampal neurons with a Sindbis virus expressing cell-filling GFP and an HA-tagged version of Nedd4-1, which displays a similar distribution to endogenous Nedd4-1 (Schwarz et al., 2010). Control neurons exhibited a diffuse pattern of Nedd4-1 staining. In contrast, neurons treated with 7PA2 CM for $23 \mathrm{~h}$ showed a robust change in Nedd4-1 distribution, characterized by a punctate pattern (CHO: $10.4 \pm$ 1.06 local maxima; 7PA2: $18.88 \pm 1.31$ local maxima; $n \geq 30$ dendrites; $p<0.001$; Fig. $2 A, B$ ) with accumulated signal in dendritic spines (7PA2, fraction of HA signal in spines normalized to CHO: $1.32 \pm 0.08, n \geq 30$ dendrites; $p=0.002$; Fig. $2 C$ ). We then used the previously mentioned biotinylation assay to assess the amount of Nedd4- 1 associated with surface proteins. We found a $3 \mathrm{~d}$ treatment with 7PA2 CM increased Nedd4-1 association with biotinylated surface proteins (normalized surface level: $1.57 \pm$ $0.17, n=3, p=0.028$; Fig. $2 D, E$ ). Collectively, these data suggest that $\mathrm{A} \beta$-induced AMPAR internalization may involve Nedd4-1mediated ubiquitination of AMPARs.

\section{Nedd4- 1 is necessary for A $\beta$-induced synaptic alterations}

To determine whether Nedd4- 1 was necessary for the synaptic deficits caused by $\mathrm{A} \beta$, we evaluated surface AMPAR levels and synaptic strength in neurons with substantially reduced Nedd4-1 levels. We used a lentivirus that expresses GFP and an shRNA hairpin to Nedd4-1, which efficiently knocks down levels of Nedd4-1 protein (Schwarz et al., 2010; Scudder et al., 2014). Cultured hippocampal neurons were infected with Nedd4-1-RNAi or control GFP virus for $4-5$ d before treating with $A \beta$ - containing or control media. A $3 \mathrm{~d}$ treatment with $250 \mathrm{~nm}$ synthetic human oligomeric $\mathrm{A} \beta$ significantly reduced mEPSC amplitude in GFP-infected control neurons (GFP+DMSO: $16.75 \pm 0.69 \mathrm{pA}, n=23$ cells; GFP $+\mathrm{A} \beta: 13.22 \pm 0.35 \mathrm{pA}, n=23$; $p<0.001$; Fig. $3 A-C$ ); however, $\mathrm{A} \beta$ failed to reduce mEPSC amplitude in Nedd4-1-RNAi-infected neurons (RNAi+DMSO: $18.03 \pm 1.01 \mathrm{pA}, n=19 ; \mathrm{RNAi}+\mathrm{A} \beta: 17.78 \pm 0.54 \mathrm{pA}, n=24$; $p=0.8$; Fig. $3 A-C)$. This suggests that Nedd4- 1 is required for $\mathrm{A} \beta$-induced reduction of synaptic strength. To test whether Nedd4-1 knockdown prevented a decrease in synaptic strength by preventing AMPAR internalization, we repeated our biotinylation assay of surface proteins. A 3 d exposure to $A \beta$ in 7PA2 $\mathrm{CM}$ significantly reduced surface GluA1 in control neurons (GFP+7PA2 normalized level: $0.85 \pm 0.04, n=5, p<0.001$; Fig. $3 D, E)$, but not in neurons infected with Nedd4-1-RNAi (RNAi+7PA2 normalized level: $1.06 \pm 0.06, n=5, p=0.3$; Fig. $3 D, E)$. This indicates that $\mathrm{A} \beta$ uses a mechanism whereby Nedd4-1 targets AMPARs to promote their internalization and decrease synaptic strength.

Because Nedd4-1 knockdown prevented $\mathrm{A} \beta$-induced internalization of surface AMPARs, which has been argued to underlie dendritic spine loss caused by A $\beta$ (Hsieh et al., 2006), we tested whether Nedd4-1 knockdown prevents $A \beta$-induced dendritic spine loss. The 7PA2 CM caused a significant decrease in spine density in control hippocampal neurons after $6 \mathrm{~d}$ of treatment (GFP+CHO: $0.72 \pm 0.02$ spines/ $\mu \mathrm{m}, n=52$ dendrites; GFP +7PA2: $0.55 \pm 0.02$ spines $/ \mu \mathrm{m}, n=46$ dendrites; $p<0.001$; Fig. $3 F, G$ ). In contrast, RNAi-mediated knockdown of Nedd 4-1 completely blocked 7PA2-induced dendritic spine loss (RNAi+CHO: $0.6 \pm 0.02$ spines $/ \mu \mathrm{m}, n=64$ dendrites; RNAi+7PA2: $0.59 \pm 0.03$ spines $/ \mu \mathrm{m}, n=53$ dendrites; $p=0.83$; Fig. $3 F, G)$. Together, these data indicate that $\mathrm{A} \beta$-induced reduction of surface AMPARs, synaptic strength, and dendritic spine density are mediated, in part, by a Nedd4-1-dependent mechanism.

\section{Discussion}

We demonstrate that exposure to low concentrations of naturally secreted $\mathrm{A} \beta$ recruited the ubiquitin ligase Nedd4-1 into 
A

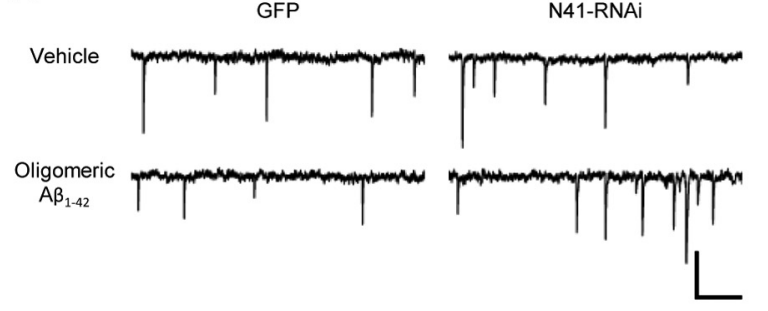

D

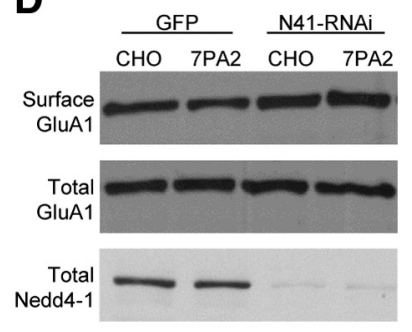

E

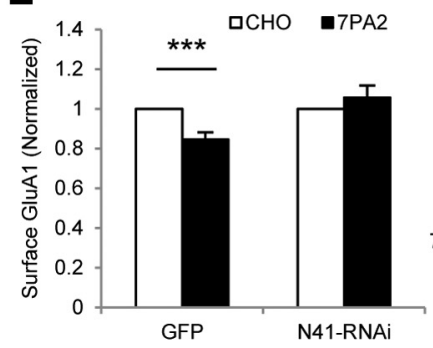

B

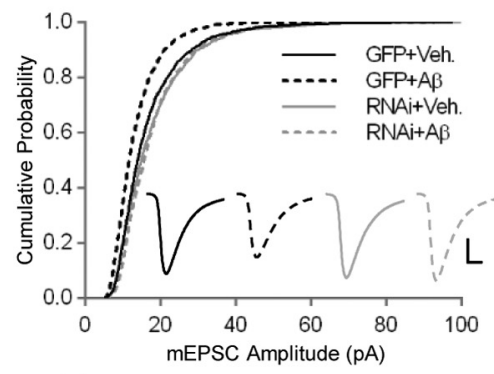

$\mathbf{F}$

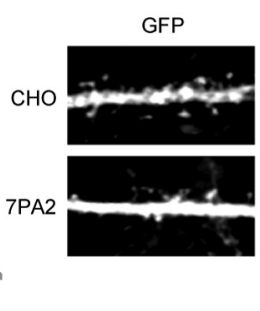

\section{C}

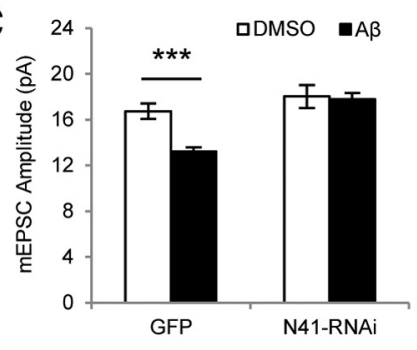

G

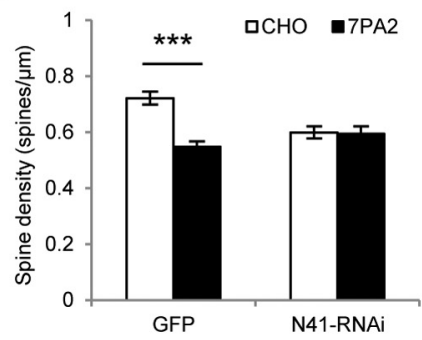

Figure 3. Nedd4-1 is necessary for $A \beta$-induced synaptic alterations. $\boldsymbol{A}$, Representative traces of mEPSCs from each condition indicated. Calibration: 500 ms, 20 pA. $\boldsymbol{B}$, Cumulative probability distributions of all mEPSC amplitudes recorded from each condition. Inset, Averaged trace for all mEPSCs in each group; $n=1960, n=2287, n=1468, n=2302$ events. Calibration: $5 \mathrm{~ms}, 5 \mathrm{pA}$. C, Mean mEPSC amplitude for cells in all conditions. D, Representative Western blot of surface GluA1 levels in neurons treated with CH0 or 7PA2 CM. $\boldsymbol{E}$, Quantification of immunoblots for surface GluA1, normalized to $\mathrm{CH} 0$ within each virus. $\boldsymbol{F}$, Representative immunofluorescent images of dendritic spines from hippocampal neurons under each of the conditions indicated. Scale bar, $5 \mu \mathrm{m}$. $\mathbf{G}$, Quantification of spine density from conditions displayed in $\boldsymbol{F} .{ }^{* *} p<0.001$.

dendritic spines, increased activity-induced ubiquitination of AMPARs, and decreased surface AMPARs. Furthermore, Nedd4-1 was required for decreased AMPAR surface expression, synaptic strength, and spine density caused by $\mathrm{A} \beta$. Our findings support the hypothesis that $\mathrm{A} \beta$-induced synaptic alterations involve, in part, Nedd4-1-mediated ubiquitination of AMPARs to promote their internalization and weaken synaptic strength.

The loss of AMPARs from synapses has been reported in $\mathrm{AD}$ patients (Carter et al., 2004) and models of amyloid pathology associated with AD (Almeida et al., 2005; Chang et al., 2006; Alfonso et al., 2014), but the mechanisms underlying $A \beta$ induced AMPAR removal remained unclear. One report demonstrated that $\mathrm{A} \beta$-induced removal of GluA2-containing AMPARs occurs via AP2- and clathrin-dependent endocytosis (Hsieh et al., 2006). We and others have previously reported that activation of AMPARs causes their ubiquitination, endocytosis, and sorting to the lysosome for degradation (Ehlers, 2000; Schwarz et al., 2010; Lussier et al., 2011; Scudder et al., 2014). In this study, we demonstrate that $\mathrm{A} \beta$ increased AMPAR ubiquitination and internalization; consequently, future studies will elucidate how $\mathrm{A} \beta$ could regulate ubiquitination of AMPARs. A $\beta$ has been shown to induce AMPAR internalization through calcium-dependent mechanisms; thus, as $\mathrm{A} \beta$-induced calcium entry may increase neuronal excitability, the downregulation of surface AMPARs may be part of a homeostatic mechanism that maintains normal levels of glutamatergic signaling (Small, 2012). Indeed, we recently demonstrated that Nedd4-1 is required for homeostatic loss of surface AMPARs (Scudder et al., 2014). Both calcium and activation of surface AMPARs are necessary for the recruitment of Nedd4-1 into dendritic spines (Scudder et al., 2014), so A $\beta$ mediated calcium entry may enhance activity-induced Nedd4-1 recruitment to synapses and ubiquitination of AMPARs. Ubiquitinated and internalized receptors usually sort to lysosomes for degradation, but we did not observe a significant decrease in total GluA1 levels. This is potentially due to an impaired lysosomal degradation system, as has been previously reported in $\mathrm{AD}$ (Nixon and Yang, 2011).
Interestingly, increased expression of Nedd4-1 has been demonstrated in response to $\mathrm{A} \beta$, as well as in $\mathrm{AD}$ brains (Kwak et al., 2012). Although we did not observe upregulation of Nedd4-1, we demonstrate that $\mathrm{A} \beta$ promoted the redistribution of Nedd4-1 into dendritic spines and increased its association with surface proteins. The functional relevance of these findings is underscored by the fact that $A \beta$ failed to induce AMPAR internalization, decreased synaptic strength, and dendritic spine loss in neurons where Nedd4-1 had been knocked down. Our results describe, for the first time, the $\mathrm{A} \beta$-mediated control of an E3 ubiquitin ligase in the regulation of surface AMPAR expression and synaptic strength. Future studies will elucidate the precise molecular mechanisms mediating Nedd4-1 ubiquitination of AMPARs in response to $\mathrm{A} \beta$. Experiments using C2-domain-mutant Nedd4-1 and lysine-mutant GluA1 will investigate whether $A \beta$-induced surface receptor downregulation requires a Nedd4-1 calcium response and receptor ubiquitination, respectively. Although our studies indicate that $A \beta$ engages Nedd4- 1 for its effects on synapses, this ligase appears to be involved in a neuron's response to several forms of toxic stress, which may ultimately contribute to diseases, such as AD, Huntington's disease, and Parkinson's disease (Kwak et al., 2012). We propose that soluble $\mathrm{A} \beta$ found in the brains of $\mathrm{AD}$ patients may cause chronic activation of Nedd4-1-mediated ubiquitination and internalization of AMPARs, contributing to the synaptic dysfunction and progressive cognitive decline associated with the disease. Testing this hypothesis in mouse models of $\mathrm{AD}$ will provide valuable insight into the mechanisms underlying synaptic deficits observed in AD.

\section{References}

Alfonso S, Kessels HW, Banos CC, Chan TR, Lin ET, Kumaravel G, Scannevin RH, Rhodes KJ, Huganir R, Guckian KM, Dunah AW, Malinow R (2014) Synapto-depressive effects of amyloid beta require PICK1. Eur J Neurosci 39:1225-1233. CrossRef Medline

Almeida CG, Tampellini D, Takahashi RH, Greengard P, Lin MT, Snyder EM, Gouras GK (2005) Beta-amyloid accumulation in APP mutant neurons 
reduces PSD-95 and GluR1 in synapses. Neurobiol Dis 20:187-198. CrossRef Medline

Carter TL, Rissman RA, Mishizen-Eberz AJ, Wolfe BB, Hamilton RL, Gandy S, Armstrong DM (2004) Differential preservation of AMPA receptor subunits in the hippocampi of Alzheimer's disease patients according to Braak stage. Exp Neurol 187:299-309. CrossRef Medline

Chang EH, Savage MJ, Flood DG, Thomas JM, Levy RB, Mahadomrongkul V, Shirao T, Aoki C, Huerta PT (2006) AMPA receptor downscaling at the onset of Alzheimer's disease pathology in double knockin mice. Proc Natl Acad Sci U S A 103:3410-3415. CrossRef Medline

Cleary JP, Walsh DM, Hofmeister JJ, Shankar GM, Kuskowski MA, Selkoe DJ, Ashe KH (2005) Natural oligomers of the amyloid-beta protein specifically disrupt cognitive function. Nat Neurosci 8:79-84. CrossRef Medline

Ehlers MD (2000) Reinsertion or degradation of AMPA receptors determined by activity-dependent endocytic sorting. Neuron 28:511-525. CrossRef Medline

Hardy J, Selkoe DJ (2002) The amyloid hypothesis of Alzheimer's disease: progress and problems on the road to therapeutics. Science 297:353-356. CrossRef Medline

Hsieh H, Boehm J, Sato C, Iwatsubo T, Tomita T, Sisodia S, Malinow R (2006) AMPAR removal underlies Abeta-induced synaptic depression and dendritic spine loss. Neuron 52:831-843. CrossRef Medline

Kwak YD, Wang B, Li JJ, Wang R, Deng Q, Diao S, Chen Y, Xu R, Masliah E, $\mathrm{Xu} \mathrm{H}$, Sung JJ, Liao FF (2012) Upregulation of the E3 ligase Nedd4-1 by oxidative stress degrades IGF-1 receptor protein in neurodegeneration. J Neurosci 32:10971-10981. CrossRef Medline

Lue LF, Kuo YM, Roher AE, Brachova L, Shen Y, Sue L, Beach T, Kurth JH, Rydel RE, Rogers J (1999) Soluble amyloid beta peptide concentration as a predictor of synaptic change in Alzheimer's disease. Am J Pathol 155:853-862. CrossRef Medline

Lussier MP, Nasu-Nishimura Y, Roche KW (2011) Activity-dependent ubiquitination of the AMPA receptor subunit GluA2. J Neurosci 31:30773081. CrossRef Medline

McLean CA, Cherny RA, Fraser FW, Fuller SJ, Smith MJ, Beyreuther K, Bush AI, Masters CL (1999) Soluble pool of Abeta amyloid as a determinant of severity of neurodegeneration in Alzheimer's disease. Ann Neurol 46: 860-866. CrossRef Medline
Nixon RA, Yang DS (2011) Autophagy failure in Alzheimer's disease, locating the primary defect. Neurobiol Dis 43:38-45. CrossRef Medline

Podlisny MB, Ostaszewski BL, Squazzo SL, Koo EH, Rydell RE, Teplow DB, Selkoe DJ (1995) Aggregation of secreted amyloid beta-protein into sodium dodecyl sulfate-stable oligomers in cell culture. J Biol Chem 270: 9564-9570. CrossRef Medline

Schwarz LA, Hall BJ, Patrick GN (2010) Activity-dependent ubiquitination of GluA1 mediates a distinct AMPA receptor endocytosis and sorting pathway. J Neurosci 30:16718-16729. CrossRef Medline

Scudder SL, Goo MS, Cartier AE, Molteni A, Schwarz LA, Wright R, Patrick GN (2014) Synaptic strength is bidirectionally controlled by opposing activity-dependent regulation of Nedd4-1 and USP8. J Neurosci 34: 16637-16649. CrossRef Medline

Selkoe DJ (2002) Alzheimer's disease is a synaptic failure. Science 298: 789-791. CrossRef Medline

Shankar GM, Li S, Mehta TH, Garcia-Munoz A, Shepardson NE, Smith I, Brett FM, Farrell MA, Rowan MJ, Lemere CA, Regan CM, Walsh DM, Sabatini BL, Selkoe DJ (2008) Amyloid-beta protein dimers isolated directly from Alzheimer's brains impair synaptic plasticity and memory. Nat Med 14:837-842. CrossRef Medline

Shepherd JD, Huganir RL (2007) The cell biology of synaptic plasticity: AMPA receptor trafficking. Annu Rev Cell Dev Biol 23:613-643. CrossRef Medline

Small DH (2012) Dysregulation of $\mathrm{Ca}^{2+}$ homeostasis in Alzheimer's disease: role in acetylcholinesterase production and AMPA receptor internalization. Neurodegener Dis 10:76-79. CrossRef Medline

Snyder EM, Nong Y, Almeida CG, Paul S, Moran T, Choi EY, Nairn AC, Salter MW, Lombroso PJ, Gouras GK, Greengard P (2005) Regulation of NMDA receptor trafficking by amyloid-beta. Nat Neurosci 8:1051-1058. CrossRef Medline

Talantova M, Sanz-Blasco S, Zhang X, Xia P, Akhtar MW, Okamoto S, Dziewczapolski G, Nakamura T, Cao G, Pratt AE, Kang YJ, Tu S, Molokanova E, McKercher SR, Hires SA, Sason H, Stouffer DG, Buczynski MW, Solomon JP, Michael S, et al. (2013) Abeta induces astrocytic glutamate release, extrasynaptic NMDA receptor activation, and synaptic loss. Proc Natl Acad Sci U S A 110:2518-2527. CrossRef Medline 